\title{
Sentinel lymph node biopsy for oral cancer
}

\author{
Jens Ahm Sørensen, Vivi Tiphede Bakholdt, Peter Grupe, Jørn Bo Thomsen \\ Department of Plastic Surgery, Odense University Hospital, Odense, Denmark \\ Correspondence to: Jens Ahm Sørensen, MD, PhD. Consultant Plastic Surgeon, Professor, Department of Plastic Surgery, Odense University Hospital, \\ J. B. Winsløvsvej 4, Odense 5000, Denmark. Email: jens.sorensen@rsyd.dk.
}

\begin{abstract}
We have used sentinel lymph node biopsy (SLNB) for oral cancer patients since 2001. Our lymphoscintigraphic, surgical as well as the histopathological examination technique has developed and been refined over the last 15 years. We use three dimensional SPECT-CT images for high accuracy identification of the sentinel lymph nodes, a simple one incision surgical approach and frozen sectioning for fast histopathological evaluation of the lymph nodes. These refinements have enabled us to perform the sentinel lymph node procedure and neck dissection in the correct patients in a same day procedure in the majority of patients.
\end{abstract}

Keywords: Sentinel lymph node biopsy (SLNB); oral cancer: lymphoscintigraphy; SPECT-CT; frozen sectioning

Received: 25 June 2018; Accepted: 23 July 2018; Published: 02 August 2018.

doi: 10.21037/jovs.2018.07.21

View this article at: http://dx.doi.org/10.21037/jovs.2018.07.21

We performed our first sentinel lymph node biopsy (SLNB) for oral cancer in April 2001. Since then we have continuously tried to develop and improve the preoperative lymphoscintigraphic imaging as well as the surgical technique. We started out applying planar images in anterior and lateral projections repeatedly over time. However, we soon added oblique planar images for better proximity and visualization of the sentinel lymph nodes. Later, we added SPECT and further a transmission scan (line source), for possible attenuation correction, and a 3D rendering image by fusing the emission and a transmission data, which showed the primary tumour and sentinel lymph nodes in relation to the body contours $(1,2)$.

The preoperative sentinel node imaging has since evolved over time regarding precision as well as in image resolution. The use of SPECT/CT allows for a more precise topographical localization of the sentinel lymph nodes (3). We now use a SPECT-CT as our standard for all sentinel lymph node procedures in the head and neck. The surgical technique has also developed and simplified using a single apron incision approach in the majority of cases. International cooperation in multicenter trials has been beneficial and has enabled us to develop and optimize the lymphoscintigraphic as well as the surgical setup (3-9).

The aim of this paper is to share our setup and surgical technique for SLNB in oral cancer developed over the last 15 years.

\section{SPECT-CT}

During the last decade sentinel node lymphoscintigraphy has evolved from simple planar imaging to the SPECT/ CT that we use today (3). The combined functional and anatomical imaging of SPECT-CT has been shown to improve the positive sentinel lymph node (PSLN) identification rate (3,10-12).

SPECT-CT has been a standard procedure for sentinel node lymphoscintigraphy for oral cancer in our institution since 2010. The operating surgeon injects the tracer, ${ }^{99 \mathrm{~m}} \mathrm{Tc}$ labeled nanocolloidal albumin (Nanocoll ${ }^{\circledR}$; GE Healthcare) in 2-4 sites in close proximity to the primary tumor. Each injection has a volume of $0.1 \mathrm{~mL}$, the total dose of injected radioactivity is $20 \mathrm{MBq}$ (Figure 1). Dynamic planar images are recorded for the first 15 minutes to ensure passage of the tracer, followed by static images if needed. The SPECT/ $\mathrm{CT}$ acquisition commences 40 minutes after tracer injection with a total scan time of $20 \mathrm{~min}$. The hotspot is marked by a permanent marker guided by the gamma camera and probe and presented to the surgeon prior to surgery. The planar and SPECT-CT images are acquired on a Siemens 


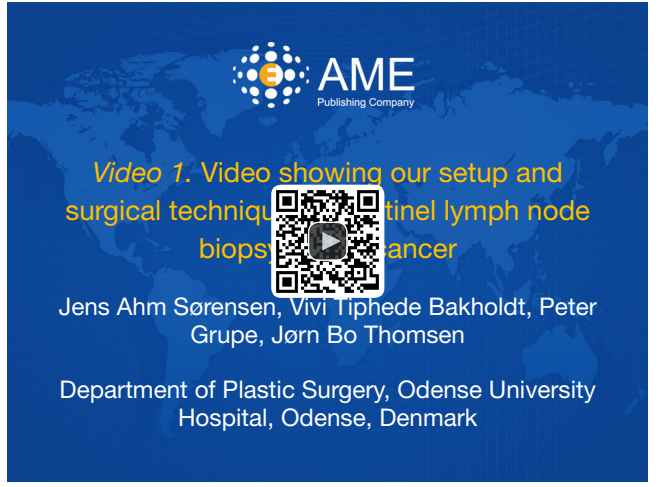

Figure 1 Video showing our setup and surgical technique for sentinel lymph node biopsy in oral cancer (13).

Available online: http://www.asvide.com/article/view/26242

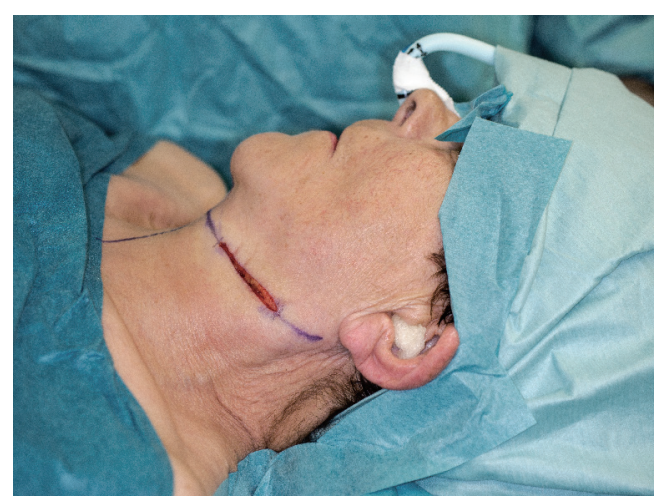

Figure 2 The incision for sentinel lymph node biopsy in the neck.

Gamma Camera (Symbia True point, Germany). Planar images are acquired in a $256 \times 256$ matrix, with a dynamic mode of 30 frames of $30 \mathrm{~s}$, and static mode $(300 \mathrm{~s})$. The SPECT-CT scan is acquired with the head and neck fixed in standard anatomical position, the SPECT protocol: matrix $128 \times 128,32$ steps, 30 seconds per step. Slice thickness: $4.8 \mathrm{~mm}$. Iterative reconstruction, Gauss filter (8 $\mathrm{mm}$ ), and resolution recovery. A low-dose CT is performed with 'Caredose' protocol, insuring standard imaging quality, (slices thickness: $3.0 \mathrm{~mm}$ ).

\section{Surgery}

\section{Excision of the primary tumour}

The patient is placed in the supine position using nasal intubation. Local anesthesia with epinephrine is injected

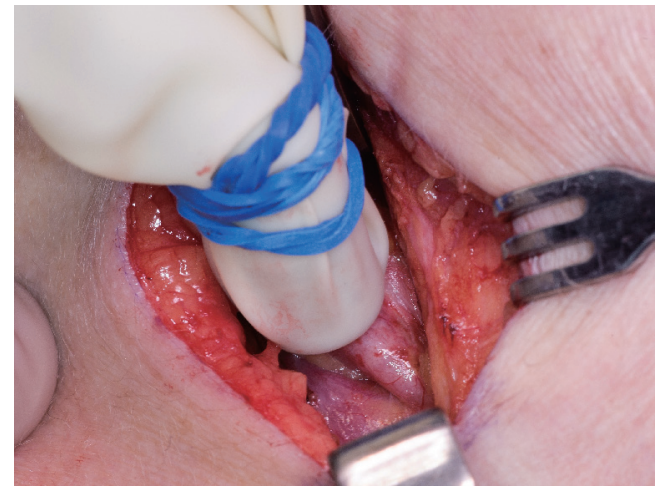

Figure 3 The gammaprobe is used to identify the sentinel lymph node.

around the circumference of the tumor. The tumour is removed with a margin of $1 \mathrm{~cm}$ by scalpel, scissors and bipolar cautery. The closure of the defect depends on the tumour size. Small defects are closed directly using an absorbable vicryl sutures. Moderate sized defects are reconstructed by local flaps, a nasolabial flap, a buccal fatpad or a free flap.

\section{$S L N B$}

The SLNB is performed through a $5 \mathrm{~cm}$ apron shaped incision, which allows us to reach the sentinel lymph nodes through one incision in most cases 9 . The marking of the incision is done in such a manner that a neck dissection can be performed in a natural extension of this incision (Figure 2). The sentinel lymph nodes are identified by a gamma probe (Figure 3). In the presented case the patients had a floor of the mouth tumor. In these patients it is particularly important to remove the primary tumour first to remove as much of the radioactivity and potential scattering prior to removal of the sentinel lymph nodes. It is often impossible to differentiate between the activity of the sentinel lymph nodes in the floor of the mouth and the activity from injection around a floor of the mouth tumour. In these cases we often choose to remove the submandibular gland as the submandibular duct most often is sacrificed in these cases anyway. We explore the region to identify the lymph nodes adjacent to the gland. Once identified and removed these lymph nodes can be tested by the gamma probe to test if these are sentinel lymph nodes. All sentinel nodes are sent for immediate pathology. They are bisected in the midline and examined by frozen section (FS) while 
the patient remains at the operating table. Hematoxylineosin $(\mathrm{H} \& \mathrm{E})$ and anti-pan cytokeratin antibody (AE1/3) is used in order to identify possible metastatic disease. If the lymph nodes contain metastatic tumour cells, the incision is extended and a neck dissection is performed.

The majority of sentinel lymph nodes from oral cancers are located in levels I to III (7). In level II-III the SNs are often located behind the sternocleidomastoid muscle (SCM) close to the jugular vein. Over time we have developed a technique in which we dissect bluntly straight through the SCM. We have found this technique to be much less invasive and faster than dissecting around the muscle. The dissection is guided by the gamma probe, which needs to be directed away from the tumor site to avoid the residual scattering which is a source of error in the detection of the sentinel lymph nodes. The sentinel lymph node is identified visually by their characteristic blank and round surface. The tissue closely adjacent to the lymph node is grasped by the forceps and the lymph node is dissected by scissor and bipolar cautery taking care not to damage the lymphatic tissue. The radioactivity of lymph node is measured in counts per second by the gamma probe to ensure that the correct lymph node has been removed. Lymph nodes with a higher radioactive count than the background activity are considered sentinel nodes. If a conglomerate of lymph nodes is removed, these are divided and tested individually by the gamma probe prior to histopathological examination. Once the desired sentinel nodes have been removed the surgical site is tested again to measure the residual radioactivity to ensure that all radioactive lymph nodes have been removed. The defect is sutured in two layers using absorbable 4.0 sutures.

\section{Discussion}

The most important prognostic factor for oral cancer is cervical lymph node metastasis which reduces the 5-year survival rate to $50 \%(14,15)$. The rate of occult cervical lymph node metastases in patients with T1-2, cNO oral cancer is $20-30 \%$ (16). These patients have previously been treated by elective neck dissection (END), but this procedure is associated with considerable morbidity, and a surgical overtreatment of approximately $70-80 \%$ of all patients with T1-2cN0 OSCC $(17,18)$.

The SLNB technique is a procedure with less morbidity than END and enables a precise cervical node staging thereby identifying the patients with metastases who can benefit from END (10). It has been demonstrated in a
European multicenter trial that the SLNB procedure in T1-2cN0 OSCC patient has an overall sensitivity of $86 \%$, a negative predictive value (NPV) of $95 \%$, and diseasefree survival of 92\% 3-year after treatment (9). The SLNB procedure can demonstrate aberrant drainage to unexpected lymph node basins such as the contralateral side which otherwise would be left untreated.

The preoperative imaging by SPECT-CT is imperative when performing SLNB in the head and neck region. We have developed the technique over the last 15 years and currently use the SPECT-CT for the preoperative visualization of the primary tumour and identification of the sentinel lymph nodes in the neck. We use both planar images as well as 3D SPECT-CT images. The sentinel lymph nodes can be identified in both the SPECT images as well as the CT-images. The image fusion allows for better identification and topographical description of the location of the sentinel lymph nodes. However, even the best of SPECT-scanners cannot identify sentinel lymph nodes located close to the injection site. In these cases the CT-images can be used to identify potential sentinel lymph nodes close to the injection site often located close to and anteriorly to the submandibular gland.

We resect the primary tumour prior to the sentinel lymph nodes aiming to remove as much of the tracer deposits around the tumour as possible. The aim of this is to minimize the radioactivity around the tumour site to reduce scattering when performing the SLNB. In patients with a tumour in the floor of the mouth the submandibular gland is often removed as the submandibular duct is often removed as a part of the tumour excision leaving the gland without function anyway. Otherwise the area is explored surgically in order to identify the lymph nodes located close to the tumour to reduce the risk of a false negative sentinel node biopsy.

\section{Conclusions}

Guided by SPECT-CT images and a gamma probe the vast majority of sentinel lymph nodes can be harvested through one apron shaped incision in the neck. The submandibular gland is often removed to locate sentinel lymph nodes close to the gland. Lymph nodes located deep to the SCM can be harvested with the least possible morbidity by blunt dissection through the muscle. In case frozen sectioning reveals a positive sentinel lymph node, the neck dissection is performed immediately. 


\section{Acknowledgments}

Funding: None.

\section{Footnote}

Conflicts of Interest: All authors have completed the ICMJE uniform disclosure form (available at http://dx.doi. org/10.21037/jovs.2018.07.21). The authors have no conflicts of interest to declare.

Ethical Statement: The authors are accountable for all aspects of the work in ensuring that questions related to the accuracy or integrity of any part of the work are appropriately investigated and resolved. All procedures performed in studies involving human participants were in accordance with the ethical standards of the institutional and/or national research committee(s) and with the Helsinki Declaration (as revised in 2013). Written informed consent was obtained from the patient for publication of this manuscript and any accompanying images.

Open Access Statement: This is an Open Access article distributed in accordance with the Creative Commons Attribution-NonCommercial-NoDerivs 4.0 International License (CC BY-NC-ND 4.0), which permits the noncommercial replication and distribution of the article with the strict proviso that no changes or edits are made and the original work is properly cited (including links to both the formal publication through the relevant DOI and the license). See: https://creativecommons.org/licenses/by-nc-nd/4.0/.

\section{References}

1. Thomsen JB, Sørensen JA, Grupe P, et al. Sentinel lymph node biopsy in oral cancer: validation of technique and clinical implications of added oblique planar lymphoscintigraphy and/or tomography. Acta Radiol 2005;46:569-75.

2. Thomsen JB, Sørensen JA, Grupe P, et al. Staging N0 oral cancer: lymphoscintigraphy and conventional imaging. Acta Radiol 2005;46:492-6.

3. Tartaglione G, Stoeckli SJ, de Bree R, et al. Sentinel Node in Oral Cancer: The Nuclear Medicine Aspects. A Survey from the Sentinel European Node Trial. Clin Nucl Med. 2016;41:534-42.

4. Ross GL, Soutar DS, Gordon MacDonald D, et al. Sentinel node biopsy in head and neck cancer: preliminary results of a multicenter trial. Ann Surg Oncol 2004;11:690-6.

5. Alkureishi LW, Burak Z, Alvarez JA, et al. Joint practice guidelines for radionuclide lymphoscintigraphy for sentinel node localization in oral/oropharyngeal squamous cell carcinoma. Ann Surg Oncol 2009;16:3190-210.

6. Alkureishi LW, Burak Z, Alvarez JA, et al. Joint practice guidelines for radionuclide lymphoscintigraphy for sentinel node localization in oral/oropharyngeal squamous cell carcinoma. Eur J Nucl Med Mol Imaging 2009;36:1915-36.

7. Alkureishi LW, Ross GL, Shoaib T, et al. Sentinel node biopsy in head and neck squamous cell cancer: 5-year follow-up of a European multicenter trial. Ann Surg Oncol 2010;17:2459-64.

8. Schilling C, Stoeckli SJ, Haerle SK, et al. Sentinel European Node Trial (SENT): 3-year results of sentinel node biopsy in oral cancer. Eur J Cancer 2015;51:2777-84.

9. Yii NW, Patel SG, Williamson P, et al. Use of apron flap incision for neck dissection. Plast Reconstr Surg 1999;103:1655-60.

10. den Toom IJ, van Schie A, van Weert S, et al. The added value of SPECT-CT for the identification of sentinel lymph nodes in early stage oral cancer. Eur J Nucl Med Mol Imaging 2017;44:998-1004.

11. Haerle SK, Hany TF, Strobel K, et al. Is there an additional value of SPECT/CT over planar lymphoscintigraphy for sentinel node mapping in oral/ oropharyngeal squamous cell carcinoma? Ann Surg Oncol 2009;16:3118-24.

12. Bilde A, Von Buchwald C, Mortensen J, et al. The role of SPECT-CT in the lymphoscintigraphic identification of sentinel nodes in patients with oral cancer. Acta Otolaryngol 2006;126:1096-103.

13. Sørensen JA, Bakholdt VT, Grupe P, et al. Video showing our setup and surgical technique for sentinel lymph node biopsy in oral cancer. Asvide 2018;5:655. Available online: http://www.asvide.com/article/view/26242

14. Broglie MA, Haerle SK, Huber GF, et al. Occult metastases detected by sentinel node biopsy in patients with early oral and oropharyngeal squamous cell carcinomas: impact on survival. Head Neck 2013;35:660-6.

15. Kovács AF, Stefenelli U, Seitz O, et al. Positive sentinel lymph nodes are a negative prognostic factor for survival in T1-2 oral/oropharyngeal cancer-a long-term study on 103 patients. Ann Surg Oncol 2009;16:233-9.

16. Shah JP. Patterns of cervical lymph node metastasis from squamous carcinomas of the upper aerodigestive tract. Am J Surg 1990;160:405-9.

17. Hernando J, Villarreal P, Alvarez-Marcos F, et al. 
Comparison of related complications: sentinel node biopsy versus elective neck dissection. Int J Oral Maxillofac Surg 2014;43:1307-12.

18. Murer K, Huber GF, Haile SR, et al. Comparison of

doi: 10.21037/jovs.2018.07.21

Cite this article as: Sørensen JA, Bakholdt VT, Grupe P, Thomsen JB. Sentinel lymph node biopsy for oral cancer. J Vis Surg 2018;4:159. morbidity between sentinel node biopsy and elective neck dissection for treatment of the $\mathrm{n} 0$ neck in patients with oral squamous cell carcinoma. Head Neck 2011;33:1260-4. 